\title{
Measurements of Carbonaceous Aerosols Using Semi-Continuous Thermal-Optical Method
}

\author{
Yu, Xiao-Ying \\ Pacific Northwest National Laboratory
}

USA

\section{Introduction}

Waste management involves collection, transport, processing, recycling, disposal, and monitoring of waste materials that can be solid, liquid, gaseous, or radioactive, which all are generated by human. It is important to monitor aerosols emitted during waste treatment and management to understand their impact on human health and the environment. Carbonaceous aerosols are major components in air pollution as a result of energy consumption, thus measurement of them is important to waste management. Increasing interest has been drawn to the identification, measurement, analysis, and modeling of carbon aerosols in the past decade. This book chapter will provide a review of the widely used semi-continuous thermal-optical method to determine carbonaceous aerosols in relation to air pollution and waste management.

Quantification of carbonaceous species provides important observations in understanding aerosol life cycle. Carbonaceous aerosols play important roles in air quality, human health, and global climate change. However, accurate measurement of carbonaceous particles still presents challenges. Carbonaceous particles are divided into three categories: organic carbon (OC), elemental carbon (EC), and inorganic carbonate carbon (CC) [Chow et al., 2005; Schauer et al., 2003]. The terms "elemental carbon (EC)", "soot", "black carbon", "graphic carbon", and "light absorbing carbon" are often used loosely and interchangeably in different research areas. Atmospheric EC particles are produced almost exclusively under incomplete combustion conditions. They are from both anthropogenic and biogenic emissions. Ambient elemental carbon particles rarely appear as diamond crystalline structure. EC aerosols absorb light effectively and they can be characterized by light scattering, absorption, or transmittance, as well as other methods. Absorption spectroscopy is deemed to provide quantitative information of EC. Difference in the definition of EC is a result of measurement methods [Jeong et al., 2004; Watson et al., 2008].

Increasingly OC has drawn more attention because of its effect on regional air pollution and global climate change. OC aerosol formation is attributed to both biogenic and anthropogenic sources [Bond \& Bergstrom, 2006]. OC may be released directly into the atmosphere (primary organic aerosol) or formed when gaseous volatile organic compounds are released to the atmosphere followed by photolysis induced oxidation to form secondary organic aerosols [Bae et al., 2004; Schauer et al., 2003]. Past findings indicate that a large 
percentage of OC observed around the world is secondary [Zhang et al., 2007]. This chapter, however, focuses on the widely used semi-continuous thermal analysis method. Comparisons among relevant methods are also provided.

\section{Thermal desorption analysis methods}

Thermal desorption has been used to analyze volatile organic compounds. The physical principle lies in the fact that different components of a sample volatize, oxidize, or react with other reagents as the temperature profile changes [MacKenzle, 1970]. Many methods employ a two-step temperature profile. Generally speaking, sample is heated in the first step to a temperature ranging from $350{ }^{\circ} \mathrm{C}$ to $850{ }^{\circ} \mathrm{C}$. Carbon evolved in this step is defined as OC. In the second step, sample is heated to a temperature ranging from $650{ }^{\circ} \mathrm{C}$ to $1100{ }^{\circ} \mathrm{C}$. Carbon evolved in this step is defined as EC. At the first temperature regime, the volatilization rate of EC is assumed to be low, and OC evolution occurs in an atmosphere without an oxidizing agent. Carbon dioxide $\left(\mathrm{CO}_{2}\right)$ gas forms as a result of OC evolving from the sample. In step 2, an oxidizer is introduced. Oxygen $\left(\mathrm{O}_{2}\right)$ is often used. EC reacts with this oxidizing agent, sometimes under catalysis conditions, to form $\mathrm{CO}_{2} . \mathrm{CO}_{2}$ is detected directly. A methane $\left(\mathrm{CH}_{4}\right)$ - helium $(\mathrm{He})$ mixture is used to calibrate the system; the $\mathrm{CH}_{4}$ is oxidized in the same manner to achieve quantification. The original compounds are transformed due to thermally-induced reactions (dissociation or oxidation). The detection is not chemically specific using the thermal analysis method. Results are often reported as empirically and operationally defined categories including OC, EC, and TC. TC is the sum of OC and EC (TC=OC+EC).

An important factor in thermal evolution methods is the OC/EC split point. Many methods use Optical Reflectance and/or Optical Transmission to monitor the conversion of OC to EC and the oxidation of $\mathrm{EC}$ to $\mathrm{CO}_{2}$. The rationale is that since $\mathrm{EC}$ is not volatile until very high temperatures (well above the $\sim 840{ }^{\circ} \mathrm{C}$ used by the NIOSH method, for example), its release is only dependent on oxidation when oxygen is present. High temperatures in the nonoxidizing environment often cause some OC components to form EC by charring. This complicates the determination of EC as additional EC is formed due to this charring. When oxygen is added to the sample oven, the black EC char will combust and the filter becomes white. When the light intensity from reflection or transmission of the samples on the filter reaches its original intensity, the charred OC is assumed to be removed. The OC/EC split point is usually defined in this manner. It is assumed what comes off after the split point is quantitatively nearly equal to the EC that was on the filter originally as EC.

Thermal-Optical methods assume that: (1) The EC caused by charring of OC's during the first $\mathrm{O}_{2}$-free step is more easily oxidized; or (2) that the absorption coefficient of the EC formed by charring is similar to the absorption coefficient of the original $\mathrm{EC}$ within the filter. If either of these assumptions is correct, then the method will be an effective quantitative method of OC and EC. Although the operational principle is similar, subtle differences exist among the different methods. These factors may include analysis atmosphere, temperature profiles, optical monitoring approaches, sample size, and other differences in physical configurations of the analytical instrument [Watson et al., 2005; Chow et al., 2005]. Some examples of more detailed studies of the effect of using TOT and TOR on the OCEC split point are discussed elsewhere [Chow et al., 2004; Cheng et al., 2009].

Particulate samples are usually collected using filters ranging from several hrs to days, then samples are prepared for off-line analysis in the laboratory. For OC and EC laboratory 
analysis, the Sunset instrument (Sunset Laboratories Inc.) and the DRI (Desert Research Institute) instrument are among the most commonly used. Near real-time or real-time online techniques are advantageous compared with off-line ones, because they provide faster sampling resolution and reduce labor in analysis. More importantly, the faster time resolution makes it possible to capture fast changing fluctuations of particle emisisons, where the off-line methods would have missed due to the longer sampling time.

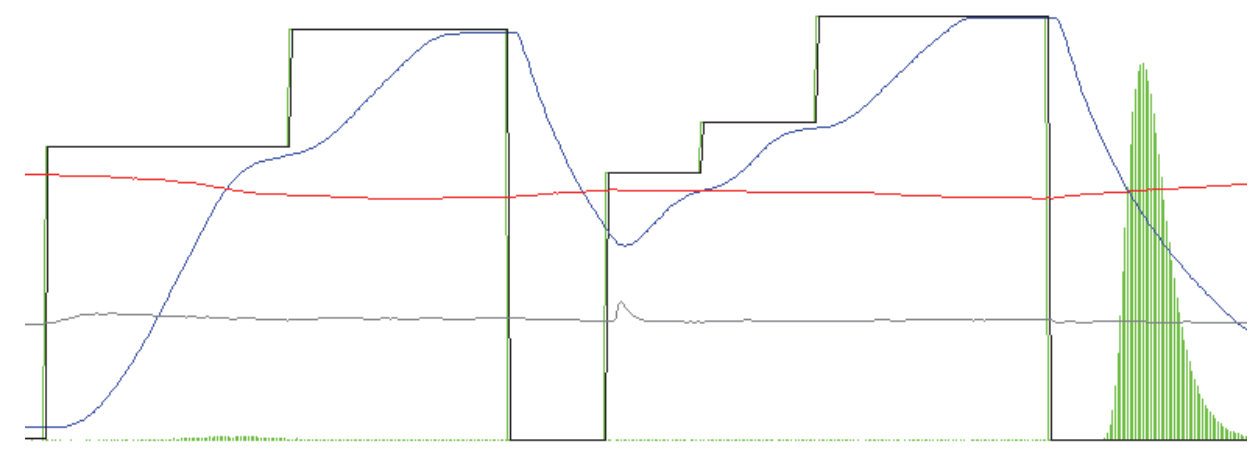

Fig. 1. An example of the modified NIOSH thermo-optical analysis thermal desorption diagram of a field sample. The $x$-axis is time in seconds, and y-axis is intensity of different traces. The blue color is oven temperature; red NDIR laser intensity; gray pressure; and green carbon dioxide.

Several techniques are established for in situ determination of black carbon (BC), such as the aethalometer and the particle soot absorption photometer. The relationship between $\mathrm{BC}$ and EC, however, is not fully resolved. These on-line EC methods do not provide OC measurements simultaneously. The Sunset Semi-Continuous Organic Carbon/Elemental Carbon (OCEC) Aerosol Analyzer has been a successful development for on-line OC and EC measurement. It can provide measurements of OC and EC on hourly time scales, and it allows for semi-continuous sampling with analysis immediately after sample collection. The instrument provides quantification of both OC and EC aerosols and requires no off-line sample treatment and laboratory analysis. This reduction in complexity, along with the ability to measure OC and EC on an hourly basis, provides advantages over conventional off-line integrated techniques.

Aerosol light absorption can be used to determine EC (or BC) either on filter media or in situ. There are several commerically avaialble instruments based on aerosol light absorption including the aethalometer, particle soot absorption photometer (PSAP), micro soot sensor, multi-angle absorption photometer (MAAP), photo-acoustic soot spectrometer (PASS), and single particle soot photometer (SP2). Moosmüller et al. [2009] provides a detailed review of these techniques. Due to the commericial avaiability of these fast in situ instruments, more comparisons have been made to the EC measurements among them. Instrument uncertainty and minimum detection limits were determined for these techniques. Some recent examples of these quantities and comparisons are seen in Chow et al. [2009], Cross et al. [2010], Slowick et al. [2007].

Other newer developments often involve mass spectrometery. One such successful example is the aerosol mass spectrometer [Jayne et al., 2000]. However, it does not provide 
simultaneous EC measurements, although it can provide faster resolution of total organic aerosol. The latter is often deduced to primary and secondary components using positive matrix factorization (PMF) analysis. As a result, it is more labor intensive to operate and conduct data reduction. In addition, MS based instruments are often more expensive to purchase. They take more power and space, therefore, not immediately accessible for longterm regulatory monitoring purpose in waste management.

\subsection{The Sunset OCEC analyzer}

The semi-continuous Sunset OCEC analyzers (Model 3F, Sunset Laboratory Inc., Portland, OR) is widely used to measure OC and EC mass loadings at different locations. Ambient samples were collected continuously by drawing a sample flow of $\sim 8 \mathrm{lpm}$. A cyclone was used upstream of the instruments to pass particles smaller than $2.5 \mu \mathrm{m}$. The airstream also passed through a denuder to remove any volatile organic compounds in the air. Sample flow rate was adjusted for the pressure difference between sea level and each of the sites to ensure accurate conversion of sample volume. During automated semi-continuous sampling, particulate matter was deposited on a quartz filter. The quartz filter was normally installed with a second backup filter, mostly to serve as support for the front filter. The portion of the sample tube containing the quartz filter was positioned within the central part of an oven, whose temperature was controlled by an instrument control and data logging program installed on a laptop computer and interfaced with the OCEC instrument.

After a sample was collected, in situ analysis was conducted by using the modified NIOSH method 5040, i.e., thermal optical transmittance analysis, to quantify OC and EC. The oven was first purged with helium after a sample was collected. The temperature inside the oven was ramped up in a step fashion to $\sim 870{ }^{\circ} \mathrm{C}$ to thermally desorb the organic compounds. The pyrolysis products were converted to carbon dioxide $\left(\mathrm{CO}_{2}\right)$ by a redox reaction with manganese dioxide. The $\mathrm{CO}_{2}$ was quantified using a self-contained non-dispersive infrared (NDIR) laser detection system. In order to quantify EC using the thermal method, a second temperature ramp was applied while purging the oven with a mixture containing oxygen and helium. During this stage, the elemental carbon was oxidized and the resulting $\mathrm{CO}_{2}$ was detected by the NDIR detection system. At the end of each analysis, a fixed volume of external standard containing methane $\left(\mathrm{CH}_{4}\right)$ was injected and thus a known carbon mass could be derived. The external calibration was used in each analysis to insure repeatable quantification. The modified NIOSH thermal-optical transmittance protocol used during a field study in Mexico City is summarized in Table 1.

Errors induced by pyrolysis of OC are corrected by continuously monitoring the absorbance of a tunable diode laser beam $(\lambda=660 \mathrm{~nm})$ passing through the sample filter. When the laser absorbance reaches the background level before the initial temperature ramping, the split point between OC and EC can be determined. OC and EC determined in this manner are defined as Thermal OC and Thermal EC. Total carbon (TC) is the sum of Thermal OC and Thermal EC, TC $=$ Thermal OC + Thermal EC, or TC=OC+EC. The Sunset OCEC analyzer also provides an optical measurement of EC by laser transmission, i.e. Optical EC. Optical OC can be derived by subtracting Optical EC from total carbon, Optical OC = TC - Optical $\mathrm{EC}$, where TC is determined in the thermal analysis.

Modifications can be made to the temperature steps in the thermal-optical method. Conny et al. [2003] conducted a study to optimize the thermal-optical method for measuring atmospheric black carbon employing surface response modeling of EC/TC, maximum laser attenuation in $\mathrm{He}$, and laser attenuation at the end of the He phase. They tried to minimize 
the positive bias from the detection of residual OC on the filter as native EC by maximizing the production OC char by the Sunset (TOT) instrument. In addition, they sought to minimize the negative bias from the loss of native EC at high temperatures. This first study concluded that for particle samples around 30 to $50 \mu \mathrm{g}$, the optimal condition for steps 1- 4 in the He environment are $190{ }^{\circ} \mathrm{C}$ for $60 \mathrm{~s}, 365^{\circ} \mathrm{C}$ for $60 \mathrm{~s}, 610^{\circ} \mathrm{C}$ for $60 \mathrm{~s}$, and $835^{\circ} \mathrm{C}$ for $72 \mathrm{~s}$, respectively.

\begin{tabular}{|c|c|c|}
\hline Carrier Gas & Duration $(\mathrm{sec})$ & Temperature $\left({ }^{\circ} \mathrm{C}\right)$ \\
\hline $\mathrm{He}-1$ & 10 & Ambient \\
\hline $\mathrm{He}-2$ & 80 & 600 \\
\hline $\mathrm{He}-3$ & 90 & 870 \\
\hline $\mathrm{He}-4$ & 25 & No Heat \\
\hline $\mathrm{O}_{2}-1$ & 30 & 600 \\
\hline $\mathrm{O}_{2}-2$ & 30 & 700 \\
\hline $\mathrm{O}_{2}-3$ & 35 & 760 \\
\hline $\mathrm{O}_{2}-4$ & 105 & 870 \\
\hline $\mathrm{CalGas}$ & 110 & No Heat \\
\hline
\end{tabular}

Table 1. An example of the modified NIOSH 5040 thermal-optical protocol used during the MILAGRO campaign [Yu et al., 2009].

Recently, Conny et al. [2009] reported an update using the same empirical factorial-based response-surface modeling approach to optimize the thermal-optical transmission analysis of atmospheric black carbon. They showed that the temperature protocol in the TOT analysis of a Sunset Instrument can be modified to distinguish pyrolyzed OC from BC based on the Beer-Lambert Law. The optimal TOT step- 4 condition in the helium environment was established to be around $830-850{ }^{\circ} \mathrm{C}$ using urban samples via response surface modeling in their newer findings, although temperature as low as $750{ }^{\circ} \mathrm{C}$ or as high as $890{ }^{\circ} \mathrm{C}$ is not excluded. This optimization is based on two criteria. First, sufficient pyrolysis of OC must occur in the high temperature helium environment (i.e., He step 4 or the high temperature step in $\mathrm{He}$ ), so that insufficiently pyrolyzed $\mathrm{OC}$ is not measured as native BC after the split point. Second, the apparent specific absorption cross sections of OC char and the apparent specific absorption cross sections of native BC determined by the instrument are assumed to be equivalent to determine the optimal operation conditions.

\subsection{Aerosol sampling inlet and field deployment}

In order to eliminate interference from near ground activities, an aerosol sampling stack can be used adjacent to the dwelling hosting the instrument at a surface site. An example is given below based on our field deployment experience. The sampling stack is made of PVC pipe $\sim 20 \mathrm{~cm}$ in diameter and extending $\sim 8 \mathrm{~m}$ above ground. The stack inlet is protected by a rain cap. A heated stainless steel sampling intake tube $(\sim 5 \mathrm{~cm}$ in diameter) is coaxially positioned in the center of stack $\sim 4 \mathrm{~m}$ below the top of the stack and extending through the lower end cap. The airflow through the aerosol sampling stack is $1000 \mathrm{lpm}$, of which approximately $120 \mathrm{lpm}$ is drawn into the heated tube. The tube is wrapped with heating tape and insulation and further encased in a PVC pipe. Electric power is applied to heat the 
sample line such that the relative humidity $(\mathrm{RH})$ of the sample air is maintained at or below $40 \%$. Much simpler design can be used to obtain equally good sampling results.

Filters are recommended to be changed every few days before the laser correction factor reached below $\sim 90 \%$. Sampling interval shall be determined based upon local mass loadings. At locations with low mass loadings that are close to the instrument detection limits, it makes sense to sample for longer time. Otherwise, for semi-real time sampling, the sample time is usually chosen to be one hour, i.e., 45-minute ambient sampling followed by 15 minutes thermal-optical analysis. Daily, at midnight, a 0-min sampling blank is taken. Instruments should be calibrated using an external filter with known OC and EC mass concentrations. Values reported are corrected to ambient temperature and pressure, this is especially important if the sampling location is elevated. Externally produced standard filters are recommended to check the precision of instrument as additional quality assurance. The relative standard deviations deduced from collocated in situ measurements between the two analyzers are determined to be 5.3\%, 5.6\%, 9.6\%, and 4.9\% for Thermal OC, Optical OC, Optical EC, and TC, respectively [Bauer et al., 2009]. The limits of detection for OC and EC determined using the thermal-optical method by the Sunset instrument were estimated to be approximately $0.2 \mu \mathrm{gC} / \mathrm{m}^{3}$ [Schauer et al., 2003]. Readers are referred to previous reviews to find more details about differences among major instruments for determination of particulate carbonaceous compositions [Chow et al., 2007].

\subsection{Thermal carbon and optical carbon}

\begin{tabular}{|l|l|l|l|l|}
\hline $\begin{array}{l}\text { Optical } \\
\text { Thermal }\end{array}$ & Slope & $\mathrm{R}^{2}$ & Locations & Reference \\
\hline OC & $0.93 \pm 0.01$ & 0.95 & Mexico City T1 & [Yu et al., 2009] \\
\hline & $0.84 \pm 0.02$ & 0.37 & Mexico City T2 & [Yu et al., 2009] \\
\hline EC & $0.89 \pm 0.02$ & 0.95 & Rochester, NY & [Jeong et al., 2004] \\
\hline & $0.99 \pm 0.07$ & 0.73 & Philadelphia, PA & [Jeong et al., 2004] \\
\hline & $0.58 \pm 0.05$ & $-^{*}$ & New York City & $\begin{array}{l}\text { [Venkatachari et al., } \\
\text { 2006] }\end{array}$ \\
\hline & $1.03^{\text {** }}$ & 0.94 & Mt. Tai, China & [Kanaya et al., 2006] \\
\hline & 0.91 & 0.84 & $\begin{array}{l}\text { 3 sites in New York \& 1 } \\
\text { site in Turkey }\end{array}$ & [Ahmed et al., 2009] \\
\hline & $1.43 \pm 0.01$ & 0.96 & Mexico City T1 & [Yu et al., 2009] \\
\hline & $1.39 \pm 0.01$ & 0.91 & Mexico City T2 & [Yu et al., 2009] \\
\hline
\end{tabular}

* Not available from the original reference

** Derived from the slope of the linear least-squares analysis of thermal EC vs. optical EC

Table 2. Linear least-squares fit parameters between quantities determined using optical and thermal-optical approaches

The thermally determined quantities are considered reliable and are used for data reporting. Some recent studies have looked into the correlation between the thermal-optically determined quantities thermal OC and thermal EC, and shown that these quantities may be strongly correlated (Table 2). Strong linear relationships have been seen at multiple locations with reasonable $\mathrm{R}^{2}$. However, the values of the fitting slope vary from $\sim 0.6$ to $\sim 1.4$. This indicates that no single simple numerical relationship can be applied everywhere. One also needs to take into consideration that some of these studies were conducted at locations of 
low EC mass loadings, which contributes to higher uncertainty in the analysis results. In the future, similar studies should be done at locations of higher carbonaceous mass loadings, which would make such comparisons more conclusive. More studies have compared the EC quantities determined by different in situ techniques. It is still an on-going effort to determine the differences among these methods [Chow et al., 2009; Cross et al., 2010; Slowick et al., 2007].

\subsection{Carbon monitoring at different locations}

Carbonaceous aerosols have been monitored by established networks in the U.S. such as the Interagency Monitoring of Protected Visual Environments (IMPROVE) and the Speciated Trends Network (STN). Many intensive field studies have been conducted to study carbonaceous aerosols in U.S. in addition to the monitoring by the long-term network. No strong correlations have been seen among OC and other major particulate matter components such as sulfate, nitrate, or ammonium ions based on a recent study compiling available ground-based carbon data worldwide [Bahadur et al., 2009]. As more attention has been directed to the importance of carbonaceous aerosols, more field data would become available.

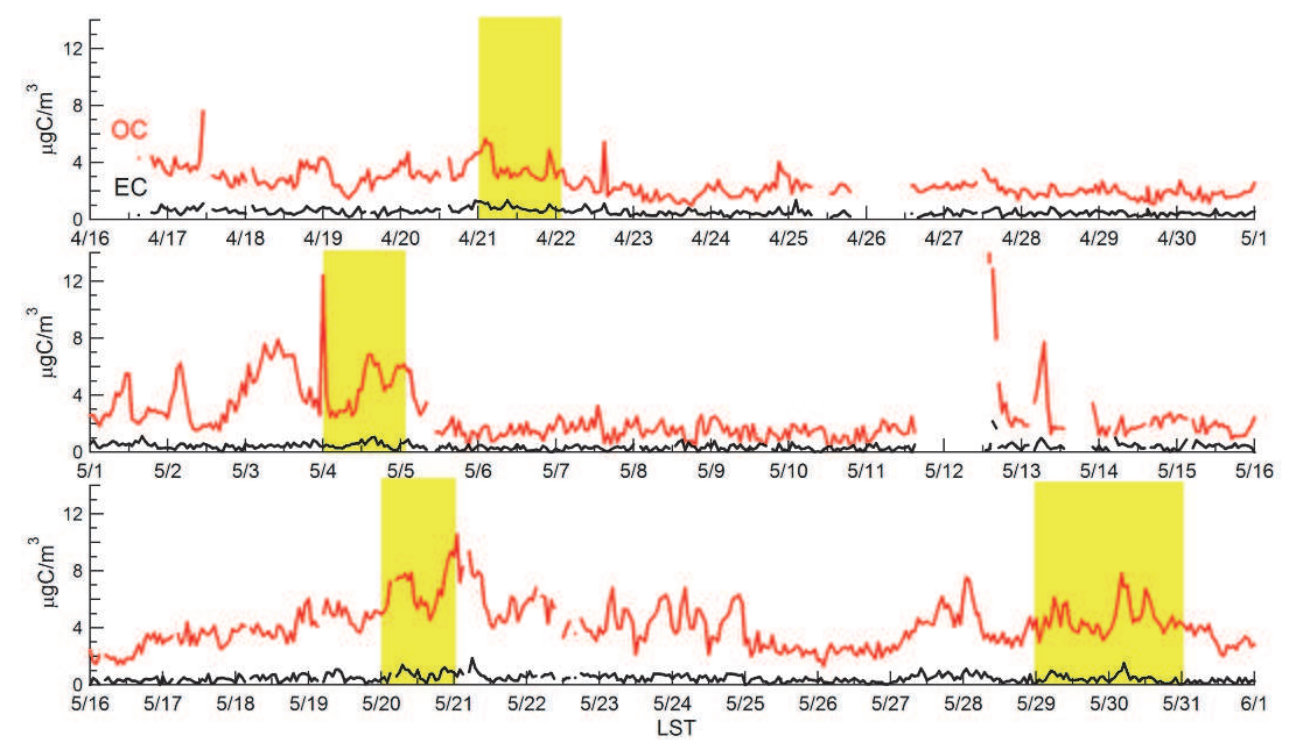

Fig. 2. Time series of organic carbon (OC) and elemental carbon (EC) measured at an urban site in Houston, TX in 2009. The yellow highlighted area indicates local ozone observation was over $75 \mathrm{ppb}$.

Table 3 shows a comparison of $\mathrm{PM}_{2.5}$ OC and EC with other metropolitan areas in the world, such as Beijing, Shanghai, Hong Kong, Los Angeles, and Houston. Most of these OC and EC measurements were obtained by thermal optical reflectance methods [Birch, 1998; Cachier et al., 1989; Chow et al., 2001]. Since the definitions of OC and EC are operationally defined, uncertainties exist among different methods. The OC:EC values for T1 and T2 reported in Table 3 are obtained by Deming regression analysis. The OC:EC value obtained at T1 is 


\begin{tabular}{|c|c|c|c|c|c|c|c|}
\hline \multirow[t]{2}{*}{ Location } & \multirow[t]{2}{*}{ OC:EC } & $\begin{array}{l}\text { OC } \\
\text { avg }\end{array}$ & $\begin{array}{l}\text { EC } \\
\text { avg }\end{array}$ & TC & \multirow[t]{2}{*}{ Season } & \multirow[t]{2}{*}{ Method } & \multirow[t]{2}{*}{ Reference } \\
\hline & & \multicolumn{3}{|c|}{$\mu \mathrm{gC} / \mathrm{m}^{3}$} & & & \\
\hline Beijing & 2.4 & 9.4 & 4.3 & -- & Summer & $\begin{array}{l}\text { Rupprecht ambient carbon } \\
\text { particulate monitor }\end{array}$ & [Yu et al., 2006] \\
\hline Beijing & 3.0 & 20.4 & 6.6 & 26.9 & Fall & $\begin{array}{l}\text { Rupprecht ambient carbon } \\
\text { particulate monitor }\end{array}$ & [Duan et al., 2005] \\
\hline Shanghai & -- & 7.9 & 3.5 & 11.4 & Summer & $\begin{array}{l}\text { Sunset OCEC analyzer NIOSH } \\
\text { protocol }\end{array}$ & [Feng et al., 2006] \\
\hline Guangzhou & -- & 14.5 & 6.3 & 20.8 & Summer & $\begin{array}{l}\text { Sunset OCEC analyzer NIOSH } \\
\text { protocol }\end{array}$ & [Feng et al., 2006] \\
\hline Hong Kong & $2-3$ & 12 & 6 & -- & Winter & $\begin{array}{l}\text { Thermal manganese dioxide } \\
\text { oxidation }\end{array}$ & [Ho et al., 2002] \\
\hline Hong Kong & 2.4 & 14.7 & 6.1 & -- & Winter & $\begin{array}{l}\text { IMPROVE thermal optical } \\
\text { reflectance method }\end{array}$ & [Cao et al., 2003] \\
\hline Houston & $2.9-4.8$ & $2.4-4.3$ & $\begin{array}{l}0.3- \\
0.6\end{array}$ & -- & All & $\begin{array}{l}\text { NIOSH thermal optical } \\
\text { reflectance method }\end{array}$ & $\begin{array}{l}\text { [Russell and Allen, } \\
\text { 2004] }\end{array}$ \\
\hline Los Angeles & 2.5 & 8.3 & 2.4 & $2--$ & Summer & $\begin{array}{l}\text { IMPROVE thermal optical } \\
\text { reflectance method }\end{array}$ & [Chow et al., 1994] \\
\hline Milan & 4.2 & 5.2 & 1.2 & -- & Summer & $\begin{array}{l}\text { NIOSH thermal optical } \\
\text { reflectance method }\end{array}$ & [Lonati et al., 2007] \\
\hline Madrid & 2.7 & 4 & 1 & -- & Summer & $\begin{array}{l}\text { EPA thermo-optical } \\
\text { transmittance technique }\end{array}$ & [Plaza et al., 2006] \\
\hline Barcelona & 2.8 & 3.9 & 1.9 & 5.8 & Summer & $\begin{array}{l}\text { Sunset OCEC analyzer NIOSH } \\
\text { protocol }\end{array}$ & [Viana et al., 2007] \\
\hline Amsterdam & 2.6 & 3.6 & 1.5 & 5.1 & Summer & $\begin{array}{l}\text { Sunset OCEC analyzer NIOSH } \\
\text { protocol }\end{array}$ & [Viana et al., 2007] \\
\hline US rural & $2.3-4.0^{*}$ & - & - & -- & Summer & $\begin{array}{l}\text { IMPROVE thermal optical } \\
\text { reflectance method }\end{array}$ & $\begin{array}{l}\text { [Schichtel et al., } \\
\text { 2008] }\end{array}$ \\
\hline US urban & $1.1-1.7^{*}$ & - & - & -- & Summer & $\begin{array}{l}\text { IMPROVE thermal optical } \\
\text { reflectance method }\end{array}$ & $\begin{array}{l}\text { [Schichtel et al., } \\
\text { 2008] }\end{array}$ \\
\hline Mexico & $1.7^{* *}$ & 9.9 & 5.8 & 15.8 & Spring & $\begin{array}{l}\text { IMPROVE thermal optical } \\
\text { reflectance method }\end{array}$ & [Chow et al., 2002] \\
\hline Mexico -T1 & -- & 3.7 & 4.0 & 16 & Spring & $\begin{array}{l}\text { IMPROVE thermal optical } \\
\text { reflectance method }\end{array}$ & $\begin{array}{l}\text { [Querol et al., } \\
\text { 2008] }\end{array}$ \\
\hline Mexico - T1 & -- & 5.0 & 1.6 & -- & Spring & $\begin{array}{l}\text { Sunset OCEC analyzer } \\
\text { modified NIOSH protocol }\end{array}$ & [Stone et al., 2008] \\
\hline Mexico - T1 & -- & 6.1 & 1.5 & 8.2 & Spring & $\begin{array}{l}\text { Sunset OCEC analyzer } \\
\text { modified NIOSH protocol }\end{array}$ & $\begin{array}{l}\text { [Hennigan et al., } \\
\text { 2008] }\end{array}$ \\
\hline Mexico - T1 & 0.9 & 6.4 & 2.1 & 8.5 & Spring & $\begin{array}{l}\text { Sunset OCEC analyzer } \\
\text { modified NIOSH protocol }\end{array}$ & [Yu et al., 2009] \\
\hline Mexico - T2 & 10.1 & 5.4 & 0.6 & 6.0 & Spring & $\begin{array}{l}\text { Sunset OCEC analyzer } \\
\text { modified NIOSH protocol }\end{array}$ & [Yu et al., 2009] \\
\hline
\end{tabular}

${ }^{*}$ Derived from EC/TC $82^{\text {nd }-98^{\text {th }}}$ percentile ratios

${ }^{* *}$ Derived from OC/TC

-- Not available from original references

Table 3. Comparison of $\mathrm{PM}_{2.5}$ OC:EC, OC, EC, and TC observed in different cities 
comparable to the average reported for urban US cities [Schichtel et al., 2008]. In contrast, the average OC:EC value at T2 is comparable to places such as Houston [Russell and Allen, 2004] and Milan [Lonati et al., 2007]. It is close to the average reported for US rural areas [Schichtel et al., 2008].

We also need to take into account the season when measurements were taken when comparing results from different locations. For example, winter observations usually result in higher mass loadings than those in summer, most likely affected by boundary layer height and mixing. For example, when looking into recent results from Mexico city, a more sensible comparison is with that in a study in Mexico in 1997 [Chow et al., 2002]. Six core sites were used in this study, La Merced, Pedregal, Xalostoc, Tlalnepantla, Netzahualcoyotl, and Cerro de la Estrella, mostly representing urban, suburban, residential, industrial, and commercial areas in or near downtown Mexico City. Results reported were averages of all six sites. The $\mathrm{T} 1$ and $\mathrm{T} 2$ comparisons with these results are in reasonable agreement. However, direct comparison with results from the regional sites may be more useful in illustrating changes or trends over the past decade. Unfortunately, the latter were not available. Querol et al. recently reported the OC and EC results during MILAGRO [Querol et al., 2008], but only results from T1 were available for comparison. Since Querol et al., [2008] selected only a few $6 \mathrm{hr}$ samples to determine OC and EC, their results do not have the same time resolution or as many samples as reported here. We expect, therefore, that the results with higher time resolution may provide more complete statistics because of the continuous hourly measurements.

\section{Data reduction}

Although the values of OC:EC and EC:TC could be used to get some idea of the extent of primary and secondary organic carbon, quantification of POC and SOC is important to assess the performance of organic aerosol predictions made by models. Identification of POC and SOC is quite important in further analysis. Due to the lack of an analytical technique for directly quantifying the atmospheric concentrations of primary organic carbon (POC) and secondary organic carbon (SOC), indirect methods have been developed to estimate their concentrations. Here we will provide detailed description of the widely used semi-empirical EC tracer method, because it is simple to use.

\subsection{The EC tracer method}

The semi-empirical EC tracer method is used to derive POC and SOC empirically. The assumptions and methodology of EC tracer method are described in detail elsewhere [Castro et al., 1999; Turpin and Huntzicker, 1991; 1995; Yu et al., 2007]. Briefly, total OC $\left(\mathrm{OC}_{\text {total }}\right)$ is defined as the sum of POC and SOC, Eq. (1).

$$
\mathrm{SOC}=\mathrm{OC}_{\text {total }}-\mathrm{POC}
$$

POC is defined in Eq. (2),

$$
\mathrm{POC}=\mathrm{EC} \times\left(\frac{O C}{E C}\right)_{p r i}
$$


where (OC:EC) pri is the estimated primary carbon ratio. The OC emitted from noncombustion sources, such as emission directly from vegetation, is assumed to be negligible in the approach used here. Using the minimum OC to EC ratio, (OC:EC) $\min$, to substitute for (OC:EC) pri, the SOC and POC can therefore be estimated [Cabada et al., 2004; Castro et al., 1999]:

$$
\mathrm{SOC}=\mathrm{OC}_{\text {total }}-\mathrm{EC} \times\left(\frac{O C}{E C}\right)_{\text {min }}
$$

Several assumptions must be made to deduce SOC and POC in this manner. For instance, samples used to calculate (OC:EC) min have negligible amounts of SOC. Composition and emission sources of POC and SOC are assumed to be relatively constant spatially and temporally. Contribution from non-combustion POC is assumed low. Contribution from semi-volatile organic compounds is also assumed to be low compared with non-volatile organic species. The determination of (OC:EC) $\min$ is crucial in this approach.

The EC tracer method is mainly dependent on ambient measurements of OC and EC and therefore is easy to use. The key is to estimate (OC:EC) pri from ambient conditions. The challenge lies determining (OC:EC) pri, because it could be influenced by meteorological conditions and emission fluctuations [Turpin and Huntzicker, 1995; Yu, S. et al., 2004].

Previous authors often used the lowest $5 \%$ or $10 \%$ measured OC/EC values in a given season to estimate (OC:EC) $\min$ [Lim and Turpin, 2002; Yuan et al., 2006]. It is worth mentioning that Yuan et al. found that (OC:EC) pri is seasonally-dependent. For instance, the (OC:EC) pri ranged from 0.41 to 0.88 from summer to winter based on observations in Hong Kong [Yuan et al., 2006]. Therefore, the (OC:EC)pri determined in a particular study could not be used in all seasons elsewhere.

In addition, other approach can be used to obtain (OC:EC) pri, since sometimes the $\mathrm{R}^{2}$ values from the lowest 5\% OC:EC approach may not be as satisfactory. For example, the linear least-squares fit results of OC vs. EC were grouped by binning OC:EC values in different ranges at the study site in Mexico City [Yu et al., 2009]. The (OC:EC) $\min =0.61$ at T1 falls in the range of OC:EC values typical of fossil fuel sources. The $\mathrm{R}^{2}$ value obtained is 0.95 . On the other hand, $(\mathrm{OC}: \mathrm{EC})_{\min }$ is 2.26 with the $\mathrm{R}^{2}=0.86$ at $\mathrm{T} 2$, a rural site in Mexico City. The (OC:EC) $\min$ value at T2 falls in the range of OC:EC values typical of biomass emissions [Gelencser et al., 2007]. The results from this approach are in reasonable agreement with those using the lowest $2.5 \%$ or $5 \%$ of OC:EC data. Since the results obtained by binning the $\mathrm{OC}$ and EC values to different ranges prior to applying linear least-squares analysis yields improved $\mathrm{R}^{2}$, the slopes from this regression analysis may be used as $(\mathrm{OC}: \mathrm{EC})_{\min }=(\mathrm{OC}: \mathrm{EC})_{\mathrm{pri}}$ to derive SOC and POC.

The intercepts from the regression analysis usually are used to estimate non-combustion POC [Cabada et al., 2004]. The uncertainty in estimating SOC and POC usually arises from random measurement errors and the statistical techniques used to derive the primary $\mathrm{OC}$ to EC ratios.

Recently several groups evaluated linear regression techniques, such as linear least-squares, Deming regression, and York regression, which are often used in the EC tracer method to derive secondary and primary organic carbon [Chu, 2005; Saylor et al., 2006]. Chu [2005] concluded that Deming fit is better when the biomass burning contribution is high. Similarly, Saylor et al. [2006] found that when limited information is available on the 
relative uncertainties of OC and EC, then Deming regression is better. Our past experience indicates that the results by using Deming fit are similar to linear regression analysis when the mass loadings are high, which results in good linear correlations independent of the regression analysis methods. When the results by linear least-squares regression and Deming regression are very comparable, results by the linear least-squares analysis can be used. Most papers report results from linear least-squares. The caveat is that the linear correlation may fall apart when the particle mass loadings are low, especially approaching the instrument detection limits. This inevitably results in more scattered data and difficulty to derive more precise conclusions.

\subsection{Other methods}

Several methods are commonly used to derive SOC and POC, including the organic tracerbased receptor model [Schauer et al., 1996; Schauer et al., 2002], the reactive chemical transport model [Pandis et al., 1992; Strader et al., 1999], the non-reactive transport model [Hildemann et al., 1996] and the semi-empirical EC tracer method [Castro et al., 1999; Turpin and Huntzicker, 1995] detailed above. Yu et al. [2004] developed a hybid approach that combines the empirical primary OC:EC ratio method with a transport/emission model of OCpri and EC, to estimate the concentrations of SOC and POC, which is termed the emission/transport of primary OC:EC ratio method.

\subsection{Comparison of SOC and POC}

In this section, we will focus on a comparison between SOC and POC results from the AMS positive matrix factorization analysis (PMF) method and EC tracer method, both of which are being used widely. Results from newer measurement techniques, such as the Aerodyne Aerosol Mass Spectrometer (AMS) [Canagaratna et al., 2007] and the Particle-Into-Liquid Sampler coupled with Total Organic Carbon analyzer (PILS-TOC), were analyzed to derive secondary organic aerosols [Sullivan et al., 2006]. The approach used by Takegawa et al. [2006], to analyze the AMS data is conceptually similar to the semi-empirical EC tracer method; whereas secondary organic aerosol (SOA) formation was inferred from direct measurements of water-soluble organic carbon (WSOC) by PILS-TOC.

A two component PMF of the AMS data results in deconvoluted OOA (oxygenated organic aerosol), HOA (hydrocarbon-like organic aerosol [Lanz et al., 2007; Ulbrich et al., 2009]. Comparisons with other gas and aerosol phase measurements at an urban site in Mexico City during the MILAGRO campaign, namely T1, indicate that the HOA component reflects primary organic aerosols generated by combustion processes (i.e., vehicle emissions and some trash/biomass burning); while the OOA component reflects secondary organic aerosol species [de Gouw et al., 2009]. In order to make a meaningful comparison between the POC, SOC, and OC determined by the Sunset OCEC field analyzer and the AMS component mass concentrations, we calculate POA and SOA concentrations taking into account of the estimated $\mathrm{OM} / \mathrm{OC}$ ratios of the two components, where OM refers to organic matter. Aiken et al. [2008] used the High Resolution ToF AMS measurements to obtain OM/OC ratios of $1.38,1.95$, and 1.55 for the HOA, OOA, and BBOA (biomass burning organic aerosol) components measured at the T0 site during the MILAGRO study. Since the HOA component at $\mathrm{T} 1$ is influenced by vehicle emissions as well as biomass burning, we estimate its $\mathrm{OM} / \mathrm{OC}$ ratio to be 1.4, the average of the $\mathrm{HOA}$ and $\mathrm{BBOA}$ values determined at $\mathrm{T} 0$ (the other urban site closer to the downtown area in Mexico City); the OM/OC ratio for the T1 OOA component is estimated to be identical to the T0 value of 1.95 . 
Figure 3 depicts the comparison of AMS HOA, OOA, and OM vs. Sunset determined POA (POC*1.4), SOA (SOC*1.95), and OM (OM=POA+SOA), respectively. The Sunset POA, SOA, $\mathrm{OM}$ are in red, and the quantities determined by AMS in blue for HOA, OOA, and OM, respectively. Scatter plots of corresponding quantities by AMS and Sunset are also presented.
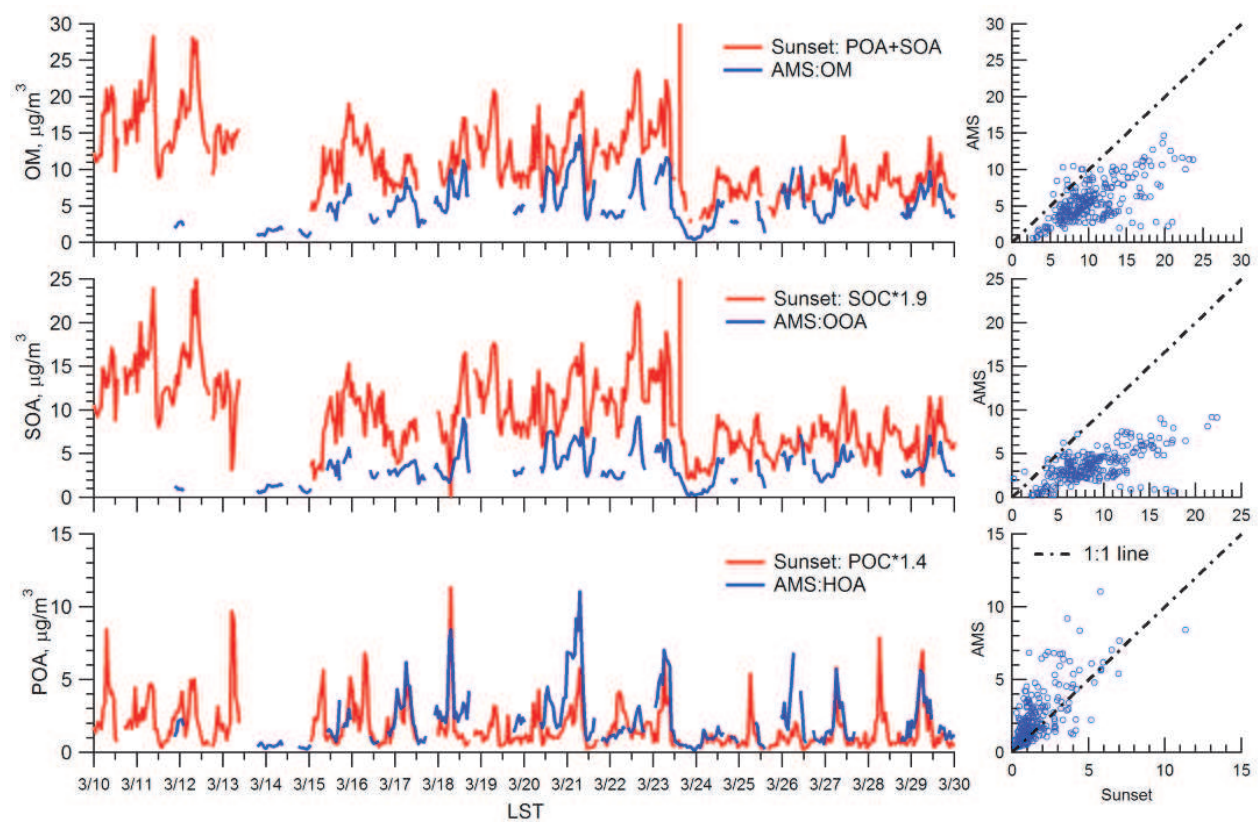

Fig. 3. Comparison of the AMS HOA, OOA, and OM vs. the Sunset POA, SOA, and OM at an urban site in Mexico City.

As to the OM comparison, several factors could contribute to these results. The first is the conversion factor used to convert $\mathrm{OC}$ to $\mathrm{OM}$ by the Sunset measurements. The Deming linear regression analysis of AMS total OM vs. Sunset OC results in a slope of 1.2 \pm 0.2 . If 1.2 were used to convert the Sunset OC to OM, the difference of the total OM determined by the AMS and those by Sunset instruments is reduced. However, recent studies by the high resolution AMS indicate that the conversion factors for POA and SOA may not be the same [Aiken et al., 2008]. Therefore, we use the sum of POA and SOA to arrive at OM. Second the size cut of AMS and the Sunset OCEC differs. The former is approximately $1 \mu \mathrm{m}$ and the latter $2.5 \mu \mathrm{m}$, which could contribute to the difference in total organic matter mass loadings. As to POA, a comparison was made between the AMS HOA vs. POA (Sunset). The general trend between the HOA and POA is in agreement over the entire field study period. As to SOA, two sets of comparison were made: AMS OOA vs. SOA (SOA=SOC*1.95) and AMS $\mathrm{OOA}$ vs. SOA (SOA=SOC$\left.{ }^{*} 1.4\right)$. One factor contributing to the difference is the conversion factor used to convert SOC to SOA. The factor determined by Aiken et al. [2008], i.e. 1.95, results in higher SOA compared with the factor 1.4 determined by an earlier review [Turpin et al., 2000]. Similarly, another factor contributing to the difference is size cut as discussed in the OM comparison. Since the OC emitted from non-combustion sources (vegetation etc.), as 
well as emissions directly from biomass burning, are assumed to be negligible in the ECtracer method, it cannot be used to derive BBOA. In future studies we should investigate the differences among different methods used to arrive at SOA and POA in more detail.

The Deming linear least-squares fit results in a slope of $0.8 \pm 0.1$ for AMS OM vs. Sunset OM, $1.2 \pm 0.2$ for AMS HOA vs. Sunset POA, $0.5 \pm 0.2$ for AMS OOA vs. Sunset SOA

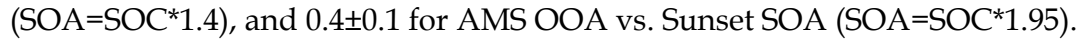

\section{Conclusion}

Thermal desorption analysis method has been widely used for the determination of carbonaceous aerosols including TC, OC, and EC for decades. It is a proven technique. Compared to the newer single particle mass spectrometery or ensemble particle mass spectrometry, it is simple to operate. Data reduction is less complicated and labor intensive unlike the mass spectrometer data deconvolution, for example. It is useful for the community to compare different thermal optical protocols to clearly define the differences among them. This will undoubtedly improve the comparability among data sets utilizing different thermal optical methods.

It is equally useful to reach consensus about the measurement difference of EC using different techniques. More research has been conducted recently, it is time more conclusive solutions be reached to make data sets more useful for experimental intercomparisons and model input. For the purpose of waste management and monitoring, it is most needed to use inexpensive, easy to operate, fast on-line analytical methods. The established semicontinous Sunset OCEC field analyzer is a good option at present. However, a smaller, more portable version may make the application and measurement of carbon aerosols more accessible to the community. As we have shown more development has been made to the in situ measurement of EC or BC in the past decades. One success is the micro Aethalometer ${ }^{\circledR}$ (Magee, model AE51). The real challenge lies in the determination of OC. Newer techniques are needed to make this happen in addition to continued effort to improve existing ones.

\section{Acknowledgment}

Support partially from the Office of Science (BER), U.S. Department of Energy, under the auspices of the Atmospheric System Research Program is gratefully acknowledged. This work was performed at the Pacific Northwest National Laboratory operated for DOE by Battelle.

\section{References}

Ahmed, T., V. A. Dutkiewicz, A. Shareef, et al. (2009), Measurement of black carbon (BC) by an optical method and a thermal-optical method: intercomparison for four sites, Atm. Environ., 43, 6305-6311.

Aiken, A. C., P. F. Decarlo, J. H. Kroll, et al. (2008), O/C and OM/OC ratios of primary, secondary, and ambient organic aerosols with high-resolution time-of-flight aerosol mass spectrometry, Environmental Science E Technology, 42(12), 4478-4485.

Allen, G. A., J. Lawrence, and P. Koutrakis (1999), Field validation of a semi-continuous method for aerosol black carbon (aethalometer) and temporal patterns of 
summertime hourly black carbon measurements in southwestern PA, Atmos. Environ., 33(5), 817-823.

Bahadur, R., G. Habib, and L. M. Russell (2009), Climatology of PM2.5 organic carbon concentrations from a review of ground-based atmospheric measurements by evolved gas analysis, Atmos. Environ., 43, 1591-1602.

Bauer, J. J., X.-Y. Yu, N. S. Laulainen, et al. (2009), Characterization of the Sunset SemiContinuous Carbon Aerosol Analyzer, Journal of Air \& Waste Management Association, 59(7), 826-833.

Baumgardner, D., G. Raga, O. Peralta, et al. (2002), Diagnosing black carbon trends in large urban areas using carbon monoxide measurements, J. Geophys. Res.-Atmos., 107(D21).

Birch, M. E. (1998), Analysis of carbonaceous aerosols: interlaboratory comparison, Analyst, 123(5), 851-857.

Bond, T. C. and R. W. Bergstrom (2006), Light absorption by carbonaceous particles: An investigative review, Aerosol Sci Technol., 40(1), 27-67.

Cabada, J. C., S. N. Pandis, R. Subramanian, et al. (2004), Estimating the secondary organic aerosol contribution to PM2.5 using the EC tracer method, Aerosol Sci. Technol., 38, 140-155.

Cachier, H., M. P. Bremond, and P. Buatmenard (1989), THERMAL SEPARATION OF SOOT CARBON, Aerosol Sci. Technol., 10(2), 358-364.

Canagaratna, M. R., J. T. Jayne, J. L. Jimenez, et al. (2007), Chemical and microphysical characterization of ambient aerosols with the aerodyne aerosol mass spectrometer, Mass Spectrom. Rev., 26(2), 185-222.

Cao, J. J., S. C. Lee, K. F. Ho, et al. (2003), Characteristics of carbonaceous aerosol in Pearl River Delta Region, China during 2001 winter period, Atmos. Environ., 37(11), 14511460.

Castro, L. M., C. A. Pio, R. M. Harrison, et al. (1999), Carbonaceous aerosol in urban and rural European atmospheres: estimation of secondary organic carbon concentrations, Atmos. Environ., 33(17), 2771-2781.

Chen, G., L. G. Huey, M. Trainer, et al. (2005), An investigation of the chemistry of ship emission plumes during ITCT 2002, J. Geophys. Res.-Atmos., 110(D10).

Chen, L. W. A., B. G. Doddridge, R. R. Dickerson, et al. (2001), Seasonal variations in elemental carbon aerosol, carbon monoxide and sulfur dioxide: Implications for sources, Geophysical Research Letters, 28(9), 1711-1714.

Cheng, Y., K. B. He, F. K. Duan, et al. (2009), Positive sampling artifact of carbonaceous aerosols and its influence on the thermal-optical split of OC/EC, Atmos. Chem. Phys., 9(18), 7243-7256.

Chow, J. C., J. G. Watson, E. M. Fujita, et al. (1994), Temporal and Spatial Variations of PM2.5 and PM10 Aerosol in the Southern California Air-Quality Study, Atmos. Environ., 28(12), 2061-2080.

Chow, J. C., J. G. Watson, D. Crow, et al. (2001), Comparison of IMPROVE and NIOSH carbon measurements, Aerosol Sci. Technol., 34(1), 23-34.

Chow, J. C., J. G. Watson, S. A. Edgerton, et al. (2002), Chemical composition of PM2.5 and PM10 in Mexico City during winter 1997, Science of the Total Environment, 287(3), 177-201. 
Chow, J. C., J. G. Watson, P. K. K. Louie, et al. (2005), Comparison of PM2.5 carbon measurement methods in Hong Kong, China, Environmental Pollution, 137(2), 334344.

Chow, J. C., J. G. Watson, D. H. Lowenthal, et al. (2006), Particulate carbon measurements in California's San Joaquin Valley, Chemosphere, 62(3), 337-348.

Chow, J. C., J. Z. Yu, J. G. Watson, et al., (2007), The application of thermal methods for determining chemical composition of carbonaceous aerosols: a review, Journal of Environmental Science and Health Part A, 42, 1521-1541.

Chow, J. C., J. G. Watson, P. Doraiswamy, et al., (2009), Aerosol light absorption, black carbon, and elemental carbon at the Fresno Supersite, California, Atm. Res., 93, 874887.

Chu, S. H. (2005), Stable estimate of primary OC/EC ratios in the EC tracer method, Atmos. Environ., 39(8), 1383-1392.

Conny, J. M., D. B. Klinedinst, S. A. Wight, J. L. Paulsen (2003), Optimizing thermal-optical methods for measuring atmospheric elemental (black) carbon: A response surface study, Aerosol Sci Technol., 37(9), 703-723.

Conny, J. M., G. A. Norris, T. R. Gould (2009), Factorial-based response-surface modeling with confidence intervals for optimizing thermal-optical transmission analysis of atmospheric black carbon, Anal Chim Acta., 635(2), 144-156.

Cornbleet, P. J., and N. Gochman (1979), Incorrect Least-Squares Regression Coefficients in Method-Comparison Analysis Clin. Chem., 25(3), 432-438.

Cross, E. S., T. B. Onash, A. Ahern, et al. (2010), Soot particle stuides instrument intercomparison project overview, Aerosol Sci. Technol., 44 (8), 592-611.

Dan, M., G. S. Zhuang, X. X. Li, et al. (2004), The characteristics of carbonaceous species and their sources in PM2.5 in Beijing, Atmos. Environ., 38(21), 3443-3452.

de Gouw, J. A., D. Welsh-Bon, C. Warneke, et al. (2009), Emission and chemistry of organic carbon in the gas and aerosol phase at a sub-urban site near Mexico City in March 2006 during the MILAGRO study, Atmos. Chem. Phys., 9(10), 3425-3442.

Duan, F. K., K. B. He, Y. L. Ma, et al. (2005), Characteristics of carbonaceous aerosols in Beijing, China, Chemosphere, 60(3), 355-364.

Feng, J. L., M. Hu, C. K. Chan, et al. (2006), A comparative study of the organic matter in PM2.5 from three Chinese megacities in three different climatic zones, Atmos. Environ., 40(21), 3983-3994.

Gelencser, A., B. May, D. Simpson, et al. (2007), Source apportionment of PM2.5 organic aerosol over Europe: Primary/secondary, natural/anthropogenic, and fossil/biogenic origin, J. Geophys. Res.-Atmos., 112(D23).

Harley, R. A., L. C. Marr, J. K. Lehner, et al. (2005), Changes in motor vehicle emissions on diurnal to decadal time scales and effects on atmospheric composition, Environ. Sci. Technol., 39(14), 5356-5362.

Hennigan, C. J., A. P. Sullivan, C. I. Fountoukis, et al. (2008), On the volatility and production mechnism of newly formed nitrate and water soluable organic aerosol in Mexico City, Atmospheric Chemistry and Physics, 8, 3761-3768.

Hildemann, L. M., W. F. Rogge, G. R. Cass, et al. (1996), Contribution of primary aerosol emissions from vegetation-derived sources to fine particle concentrations in Los Angeles, J. Geophys. Res.-Atmos., 101(D14), 19541-19549. 
Ho, K. F., S. C. Lee, J. C. Yu, et al. (2002), Carbonaceous characteristics of atmospheric particulate matter in Hong Kong, Science of the Total Environment, 300(1-3), 59-67.

Jayne, J.T., D.C. Leard, X. Zhang, P. Davidovits, K.A. Smith, C.E. Kolb, and D.R. Worsnop (2000), Development of an aerosol mass spectrometer for size and composition analysis of submicron particles, Aerosol Sci. Technol., 33, 49-70.

Jeong, C. H., P. K. Hopke, E. Kim, et al. (2004), The comparison between thermal-optical transmittance elemental carbon and Aethalometer black carbon measured at multiple monitoring sites, Atmos. Environ., 38(31), 5193-5204.

Kanaya, Y., Y. Komazaki, P. Pochanart, et al. (2008), Mass concentrations of black carbon measured by four instruments in the middle of Central East China in June 2006, Atmos. Chem. Phys., 8, 7637-7649.

Lanz, V. A., M. R. Alfarra, U. Baltensperger, et al. (2007), Source apportionment of submicron organic aerosols at an urban site by factor analytical modelling of aerosol mass spectra, Atmos. Chem. Phys., 7(6), 1503-1522.

Lim, H. J., and B. J. Turpin (2002), Origins of primary and secondary organic aerosol in Atlanta: Results' of time-resolved measurements during the Atlanta supersite experiment, Environ. Sci. Technol., 36(21), 4489-4496.

Lonati, G., S. Ozgen, and M. Giugliano (2007), Primary and secondary carbonaceous species in PM2.5 samples in Milan (Italy), Atmos. Environ., 41(22), 4599-4610.

MacKenzle, R. C. (1970), Differential thermal analysis Vol. 1: Fundamental Aspects New York: Academic Press.

Martin, R. (2000), General Deming Regression for Estimating Systematic Bias and Its Confidence Interval in Method-Comparison Studies, Clin. Chem., 46(1), 100-104.

Moosmüller, H., R. K. Chakrabarty, and W. P. Arnott (2009), Aerosol light absorption and its measurement: a review, J. Quantitative Spectroscopy \& Radiative Transfer, 110, 844878.

Nunnermacker, L. J., D. Imre, P. H. Daum, et al. (1998), Characterization of the Nashville urban plume on July 3 and July 18, 1995, J. Geophys. Res.-Atmos., 103(D21), 2812928148.

Pandis, S. N., R. A. Harley, G. R. Cass, et al. (1992), Secondary Organic Aerosol Formation and Transport, Atmospheric Environment Part a-General Topics, 26(13), 2269-2282.

Park, S. S., M. S. Bae, J. J. Schauer, et al. (2005a), Evaluation of the TMO and TOT methods for OC and EC measurements and their characteristics in PM2.5 at an urban site of Korea during ACE-Asia, Atmos. Environ., 39(28), 5101-5112.

Park, S. S., D. Harrison, J. P. Pancras, et al. (2005b), Highly time-resolved organic and elemental carbon measurements at the Baltimore Supersite in 2002, J. Geophys. Res.Atmos., 110(D7).

Patashnick, H., and E. G. Rupprecht (1991), CONTINUOUS PM-10 MEASUREMENTS USING THE TAPERED ELEMENT OSCILLATING MICROBALANCE, J. Air Waste Manage. Assoc., 41(8), 1079-1083.

Plaza, J., F. J. Gomez-Moreno, L. Nunez, et al. (2006), Estimation of secondary organic aerosol formation from semicontinuous OC-EC measurements in a Madrid suburban area, Atmos. Environ., 40(6), 1134-1147.

Querol, X., J. Pey, M. C. Minguillon, et al. (2008), PM speciation and sources in Mexico during the MILAGRO-2006 Campaign, Atmospheric Chemistry and Physics, 8(1), 111128. 
Russell, M., and D. T. Allen (2004), Seasonal and spatial trends in primary and secondary organic carbon concentrations in southeast Texas, Atmos. Environ., 38(20), 32253239.

Salma, I., X. G. Chi, and W. Maenhaut (2004), Elemental and organic carbon in urban canyon and background environments in Budapest, Hungary, Atmos. Environ., 38(1), 27-36.

Saylor, R. D., E. S. Edgerton, and B. E. Hartsell (2006), Linear regression techniques for use in the EC tracer method of secondary organic aerosol estimation, Atmos. Environ., 40(39), 7546-7556.

Schauer, J. J., W. F. Rogge, L. M. Hildemann, et al. (1996), Source apportionment of airborne particulate matter using organic compounds as tracers, Atmos. Environ., 30(22), 3837-3855.

Schauer, J. J., M. P. Fraser, G. R. Cass, et al. (2002), Source reconciliation of atmospheric gasphase and particle-phase pollutants during a severe photochemical smog episode, Environ. Sci. Technol., 36(17), 3806-3814.

Schauer, J. J., B. T. Mader, J. T. Deminter, et al. (2003), ACE-Asia intercomparison of a thermal-optical method for the determination of particle-phase organic and elemental carbon, Environ. Sci. Technol., 37(5), 993-1001.

Schichtel, B. A., W. C. Malm, G. Bench, et al. (2008), Fossil and contemporary fine particulate carbon fractions at 12 rural and urban sites in the United States, J. Geophys. Res.Atmos., 113(D2).

Slowick, J. G., E. S. Cross, J. H. Han, et al. (2007), An inter-comparison of instruments measuring black carbon content of soot particles, Aerosol Sci. Technol., 41(3), 295314.

Stone, E. A., D. C. Snyder, R. J. Sheesley, et al. (2008), Source apportionment of fine organic aerosol in Mexico City during the MILAGRO experiment 2006, Atmospheric Chemistry and Physics, 8, 1249-1269.

Strader, R., F. Lurmann, and S. N. Pandis (1999), Evaluation of secondary organic aerosol formation in winter, Atmos. Environ., 33(29), 4849-4863.

Sullivan, A. P., R. E. Peltier, C. A. Brock, et al. (2006), Airborne measurements of carbonaceous aerosol soluble in water over northeastern United States: Method development and an investigation into water-soluble organic carbon sources, $J$. Geophys. Res.-Atmos., 111(D23).

Takegawa, N., T. Miyakawa, Y. Kondo, et al. (2006), Seasonal and diurnal variations of submicron organic aerosol in Tokyo observed using the Aerodyne aerosol mass spectrometer, Journal of Geophysical Research-Atmospheres, 111(D11).

Turpin, B. J., and J. J. Huntzicker (1991), SECONDARY FORMATION OF ORGANIC AEROSOL IN THE LOS-ANGELES BASIN - A DESCRIPTIVE ANALYSIS OF ORGANIC AND ELEMENTAL CARBON CONCENTRATIONS, Atmospheric Environment Part a-General Topics, 25(2), 207-215.

Turpin, B. J., J. J. Huntzicker, S. M. Larson, et al. (1991), LOS-ANGELES SUMMER MIDDAY PARTICULATE CARBON - PRIMARY AND SECONDARY AEROSOL, Environ. Sci. Technol., 25(10), 1788-1793.

Turpin, B. J., and J. J. Huntzicker (1995), Identification of Secondary Organic Aerosol Episodes and Quantitation of Primary and Secondary Organic Aerosol Concentrations During Scaqs, Atmos. Environ., 29(23), 3527-3544. 
Turpin, B. J., P. Saxena, and E. Andrews (2000), Measuring and simulating particulate organics in the atmosphere: problems and prospects, Atmos. Environ., 34(18), 29833013.

Ulbrich, I. M., M. R. Canagaratna, Q. Zhang, et al. (2009), Interpretation of organic components from Positive Matrix Factorization of aerosol mass spectrometric data, Atmos. Chem. Phys., 9(9), 2891-2918.

Venkatachari, P., L. Zhou, P. K. Hopke, et al. (2006), An intercomparison of measurement methods for carbonaceous aerosol in the ambient air in New York City, Aerosol Sci. Technol., 40, 788-795

Viana, M., W. Maenhaut, H. M. ten Brink, et al. (2007), Comparative analysis of organic and elemental carbon concentrations in carbonaceous aerosols in three European cities, Atmos. Environ., 41(28), 5972-5983.

Wang, T., C. H. Wong, T. F. Cheung, et al. (2004), Relationships of trace gases and aerosols and the emission characteristics at Lin'an, a rural site in eastern China, during spring 2001, J. Geophys. Res.-Atmos., 109(D19).

Watson, J. G., and J. C. Chow (2002), A wintertime PM2.5 episode at the fresno, CA, supersite, Atmos. Environ., 36(3), 465-475.

Watson, J. G., J. C. Chow, and L.-W.A. (2005), Summary of organic and elemental carbon/black carbon analysis methods and intercomparisons, Aerosol and Air Quality Research, 5(1), 65-102.

$\mathrm{Yu}$, J. H., T. Chen, B. Guinot, et al. (2006), Characteristics of carbonaceous particles in Beijing during winter and summer 2003, Advances in Atmospheric Sciences, 23(3), 468-473.

Yu, J. Z., J. W. T. Tung, A. W. M. Wu, et al. (2004), Abundance and seasonal characteristics of elemental and organic carbon in Hong Kong PM10, Atmos. Environ., 38(10), 15111521.

Yu, S., R. L. Dennis, P. V. Bhave, et al. (2004), Primary and secondary organic aerosols over the United States: estimates on the basis of observed organic carbon (OC) and elemental carbon (EC), and air quality modeled primary OC/EC ratios, Atmos. Environ., 38(31), 5257-5268.

Yu, S., P. V. Bhave, R. L. Dennis, et al. (2007), Seasonal and regional variations of primary and secondary organic aerosols over the Continental United States: Semi-empirical estimates and model evaluation, Environ. Sci. Technol., 41(13), 4690-4697.

Yu, X.-Y., R. A. Cary, and N. S. Laulainen (2009), Primary and secondary organic carbon downwind of Mexico City, Atmos. Chem. Phys., 9, 6793-6814.

Yuan, Z. B., J. Z. Yu, A. K. H. Lau, et al. (2006), Application of positive matrix factorization in estimating aerosol secondary organic carbon in Hong Kong and its relationship with secondary sulfate, Atmospheric Chemistry and Physics, 6, 25-34.

Zhang, Q., J. L. Jimenez, M. R. Canagaratna MR, et al. (2007), Ubiquity and dominance of oxygenated species in organic aerosols in anthropogenically-influenced Northern Hemisphere midlatitudes, Geophys Res Lett., 34, L13801. 


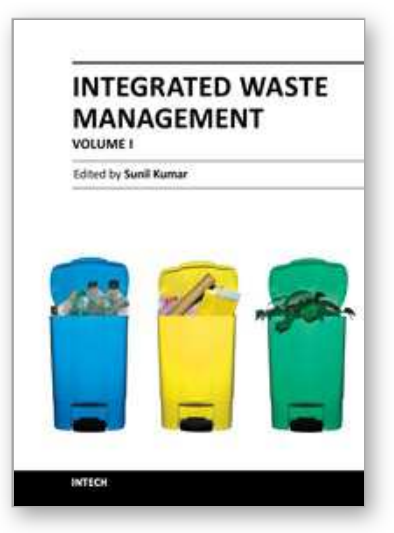

\author{
Integrated Waste Management - Volume I \\ Edited by Mr. Sunil Kumar
}

ISBN 978-953-307-469-6

Hard cover, 538 pages

Publisher InTech

Published online 23, August, 2011

Published in print edition August, 2011

This book reports research on policy and legal issues, anaerobic digestion of solid waste under processing aspects, industrial waste, application of GIS and LCA in waste management, and a couple of research papers relating to leachate and odour management.

\title{
How to reference
}

In order to correctly reference this scholarly work, feel free to copy and paste the following:

Xiao-Ying Yu (2011). Measurements of Carbonaceous Aerosols Using Semi-Continuous Thermal-Optical Method, Integrated Waste Management - Volume I, Mr. Sunil Kumar (Ed.), ISBN: 978-953-307-469-6, InTech, Available from: http://www.intechopen.com/books/integrated-waste-management-volume-i/measurements-ofcarbonaceous-aerosols-using-semi-continuous-thermal-optical-method

\section{INTECH}

open science | open minds

\section{InTech Europe}

University Campus STeP Ri

Slavka Krautzeka 83/A

51000 Rijeka, Croatia

Phone: +385 (51) 770447

Fax: +385 (51) 686166

www.intechopen.com

\section{InTech China}

Unit 405, Office Block, Hotel Equatorial Shanghai

No.65, Yan An Road (West), Shanghai, 200040, China

中国上海市延安西路65号上海国际贵都大饭店办公楼405单元

Phone: +86-21-62489820

Fax: +86-21-62489821 
(C) 2011 The Author(s). Licensee IntechOpen. This chapter is distributed under the terms of the Creative Commons Attribution-NonCommercialShareAlike-3.0 License, which permits use, distribution and reproduction for non-commercial purposes, provided the original is properly cited and derivative works building on this content are distributed under the same license. 